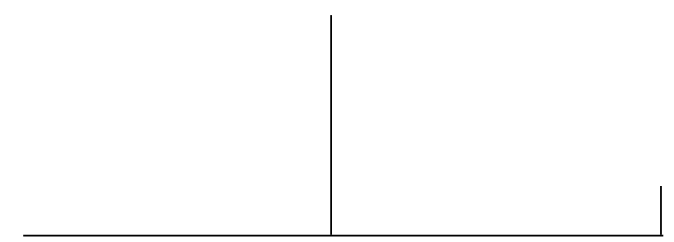

Rev. Latinoam. Psicopat. Fund., São Paulo, v. 13, n. 3, p. 395-411, setembro 2010

\title{
Análise do desamparo de uma menina de cinco anos*
}

\author{
Diana Dadoorian \\ Fernanda Hamann de Oliveira \\ Viviane Chan
}

Neste artigo apresentamos o método de trabalho desenvolvido em um ambulatório público especializado no atendimento psicanalítico de crianças, relatando o caso clínico de uma menina de cinco anos. Este estudo mostra a importância de uma metodologia específica para o tratamento psicanalítico da criança, onde a criança $e$ os seus pais são atendidos pelo mesmo psicólogo, em horários diferentes. As conclusões apontam a relevância desta modalidade de atendimento para a saúde mental da criança.

Palavras-chave: Psicanálise de criança, ambulatório público, atendimento aos pais

* Artigo apresentado na Sessão Clínica do Instituto de Psiquiatria da UFRJ, no dia 2 de dezembro de 2008. 


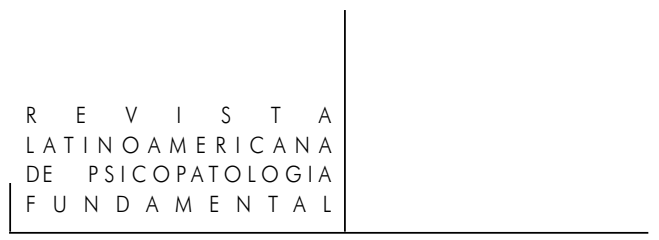

\section{Introdução}

A psicanálise com crianças, embora colecione contribuições seminais de autores do calibre de Donald Winnicott e Melanie Klein, parece ocupar, no campo psicanalítico tradicional, um espaço secundário em relação à psicanálise com adultos. Se concordarmos com a assertiva lacaniana de que o lugar ocupado pela criança é aquele de sintoma da família (Lacan, 1986), podemos até mesmo nos questionar se não seria mais adequado que os membros da família em questão entrassem em análise, em vez da criança que dá a ver suas formações de compromisso.

O próprio Freud (1909) sustentou uma posição semelhante na condução do famoso caso do Pequeno Hans, seu mais importante legado à psicanálise com crianças. A rigor, Freud era analista do pai de Hans e recebeu o menino de cinco anos em seu consultório não mais do que uma única vez, tendo conduzido sua análise principalmente pela interlocução com seu pai. No relato deste caso, Freud sublinha, justamente, a relevância deste aspecto facilmente constatado pelo analista em função junto aos pequeninos: a importância de uma interlocução direta com seus pais ou responsáveis.

No entanto, não é a esta interlocução que se resume, hoje, a prática mais difundida em psicanálise com crianças. A periodicidade dos encontros com os pais pode variar segundo diferentes linhas de orientação, ou mesmo segundo o caso a caso, podendo ser semanal, quinzenal, mensal, e assim por diante. Não obstante, o foco de atenção da análise é centrado na criança, a partir da aposta na sua capacidade, enquanto sujeito, de recordar, repetir e elaborar as situações traumáticas por ela vivenciadas (Freud, 1914).

Desenvolvida por psicanalistas pós-freudianos, em particular por Melanie Klein, a técnica do brincar - potencialmente tão reveladora da dinâmica inconsciente quanto a associação livre - tornou possível a criação de um dispositivo especializado onde, conforme se verifica nitidamente na clínica, muitos efeitos se produzem a partir da interação com a própria criança. 
Este tipo de prática é sustentado no programa Psicanálise de criança, no âmbito do Serviço de Psiquiatria da Infância e da Adolescência (SPIA) do Instituto de Psiquiatria da Universidade Federal do Rio de Janeiro (IPUB/UFRJ). No ambulatório do serviço, as crianças são recebidas em entrevistas de triagem que buscam avaliar sua demanda de tratamento, para que ocorra um encaminhamento à psiquiatria, à psicanálise, a ambas, ou a algum serviço externo ao instituto (neurologia, pedagogia, pediatria etc.).

No presente artigo, apresentaremos o método de trabalho desenvolvido no programa Psicanálise de criança, relatando o estudo e andamento do caso clínico de Caroline, uma menina de cinco anos. A experiência adquirida mostrou a importância para o tratamento psicanalítico da criança de uma metodologia específica, onde ela e os seus pais são atendidos pelo mesmo psicólogo, em horários diferentes, como veremos a seguir.

Neste trabalho de equipe, as psicólogas são alunas do Curso de Especialização em Saúde Mental da Infância e Adolescência do SPIA/IPUB/UFRJ. Fernanda Hamann de Oliveira atuou como psicanalista de Caroline e realizou também o atendimento a seu pai, Rodrigo. Viviane Chan, por sua vez, atuou como psicanalista de Rodrigo. Ambas relatam, adiante, detalhes sobre o caso, supervisionado por Diana Dadoorian, psicanalista e coordenadora do programa Psicanálise de criança do SPIA/IPUB/UFRJ.

Entrevistas preliminares (out-dez/2007) ${ }^{1}$

Em uma entrevista de triagem (em 30/10/2007), conheci Caroline, na época com quatro anos e hoje prestes a completar seis. Já durante a entrevista, percebi que seu processo de análise exigiria um trabalho paralelo com seu pai, Rodrigo, 36 anos. Enquanto me fornecia os dados solicitados pela ficha de plantão, ele também, ao lado dela, distraía-se fazendo um desenho em uma das folhas brancas que eu oferecera a Caroline. Desenhou uma casa, como o fazem espontaneamente tantas crianças - e evidenciando este algo que há de infantil em nós, adultos -, mas uma espécie de casa voadora, dispersa, sem chão e sem rumo, numa parte restrita do papel (Fig. 1). Ele não soube o que dizer desta casa, quando lhe perguntei: "Não sei explicar", falou rindo, "É nervoso!". Mas eu logo viria a saber, ao longo da entrevista, que ela parecia dizer da própria infância e adolescência de

1. Atendimento realizado e relatado por Fernanda Hamann de Oliveira.

Rev. Latinoam. Psicopat. Fund., São Paulo, v. 13, n. 3, p. 395-411, setembro 2010 
Rodrigo: tanto ele quanto a mãe de Caroline - Flávia, 24 anos - haviam perambulado por muitos anos na rua, sem lar.

Figura 1

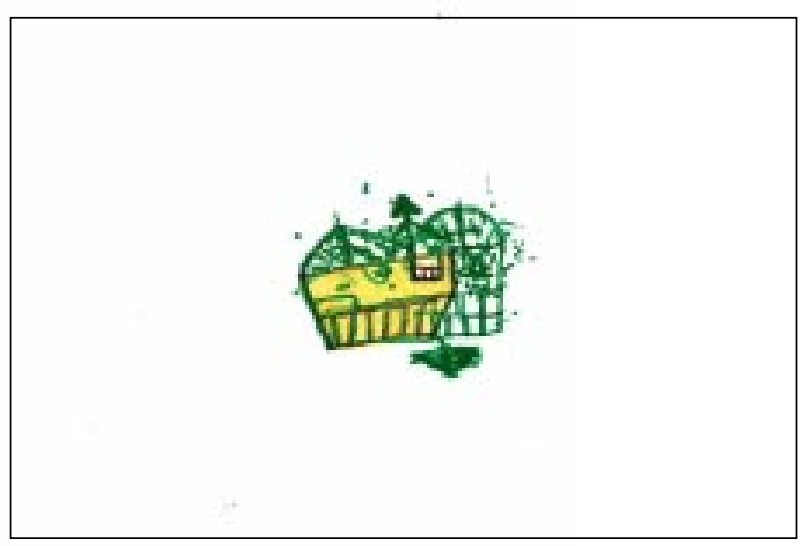

Caroline, por sua vez, desenhou nada mais do que poucos traços, débeis e não figurativos (Fig. 2). Tinha a aparência relativamente bem cuidada e saudável, e respondia prontamente a minhas perguntas. Seu desenvolvimento psicomotor ocorreu sem grandes percalços e sem tratamentos anteriores, não havendo qualquer queixa quanto a sintomas relacionados à alimentação, ao sono, à inteligência ou à linguagem.

Figura 2

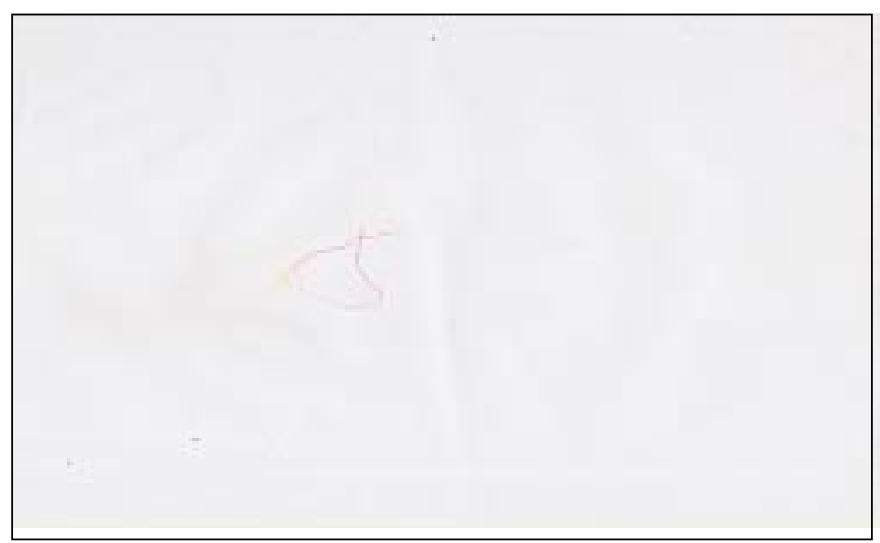

Rev. Latinoam. Psicopat. Fund., São Paulo, v. 13, n. 3, p. 395-411, setembro 2010 
A queixa principal, relatada por seu pai, advinha da escola: “... péssimo comportamento", "beliscou a professora", "bate nos colegas", "não obedece"... Em suma: a escola só aceitaria Caroline de volta com a garantia de que ela iniciasse um tratamento psicológico. Neste dia, ela completava duas semanas sem aulas. Este fato, em si só, chama a atenção para uma certa rigidez por parte da escola, que apresentou dificuldades de lidar com a posição negativista de Caroline - o que não é raro nesta idade, quando as crianças testam seu poder de contrariar os adultos, embora no caso de Caroline esta tentativa tenha se manifestado de forma tão intensa.

Durante toda a entrevista, Caroline escutava com atenção tudo o que era dito a seu respeito, fazendo pequenos comentários eventuais. Ela se mostrou esperta e cooperativa, ajudando-me de bom grado a guardar os lápis de cor e aproximando-se de mim para examinar meu rosto de perto e me dar um carinhoso beijo na bochecha, por iniciativa própria. Surpreendia-me, por um lado, a discrepância entre esta criança tão doce e aquela criança agressiva e desobediente que o pai descrevia. E também me surpreendia, por outro lado, a rapidez com que se estabeleceu um laço transferencial entre nós: ela parecia querer seduzir-me, dirigindo-me uma clara demanda de amor (ou de tratamento); eu cedia à sua doçura que, aliás, conquista inúmeros admiradores entre os profissionais e frequentadores do ambulatório -, desde logo desejosa de atendê-la.

Entretanto, bastou que eu lhe perguntasse sobre a escola e suas feições se modificaram instantaneamente. Apagou-se o sorriso, que deu lugar a uma expressão, a um só tempo, triste e zangada, com a testa franzida e os lábios cerrados. Em silêncio, sem responder, Caroline me ouvia perguntar-lhe o que havia de tão terrível na escola para que ela ficasse assim tão brava só de ouvir falar no assunto. Alguns segundos depois, ela começou a chorar e se dirigiu à porta, para abandonar a sala. Levantei-me e andei em sua direção, dizendo que eu havia entendido que esse assunto era difícil para ela, e que não precisávamos tocar nele agora, mas voltaríamos a conversar sobre isso mais tarde. Ela me escutou e parou de chorar, permanecendo tranquilamente na sala até o fim da entrevista.

Segundo Rodrigo, os sintomas haviam surgido no ano anterior, quando Caroline passou a frequentar a creche. Como se sabe, este pode ser um momento traumático para muitas crianças, que reagem a ele de formas diversas. A reação de Caroline foi a de se tornar agressiva: certo dia, sem motivo aparente, negou-se a tomar banho na creche; cuspiu na diretora; recusou-se a obedecer qualquer pessoa. O pai foi chamado a buscá-la, e a encontrou nua, chorosa e "toda mijada" (sic). Aos três anos, Caroline recebeu sua primeira suspensão, que durou quase um mês. 
Enquanto relatava a evolução dos sintomas, garantindo que em casa - a família mora na favela da Rocinha - Caroline demonstrava um comportamento normal, Rodrigo se acalmava aos poucos. Isso porque, quando convidei os dois para entrar na sala, ele estava enfurecido com minha demora em atendê-los, devido à fila de espera do plantão. Ao longo dos atendimentos, esta fúria se repetia a qualquer pequeno atraso de minha parte, e igualmente se dissipava ao longo da sessão, à medida que eu escutava o que Rodrigo tinha a dizer. Discutindo o fato em supervisão, compreendi que sua drástica oscilação de humor expressava seu medo de ser abandonado, de retornar ao desamparo de um menino que nunca foi "criado" pela mãe ou pelo pai (alcoólatra), um menino que "[se criou] na rua", de acordo com suas próprias palavras. As marcas deste desamparo se faziam evidentes no rosto de Rodrigo, repleto de cicatrizes, duas ou três mais profundas. E também no seu esforço visível para construir um lar, muito embora não tivesse jamais contado com um modelo exemplar que pudesse eleger como ideal.

Enquanto Flávia trabalhava como diarista, era ele quem se ocupava dos quatro filhos do casal - eram cinco, mas uma das crianças faleceu a um ano de idade, vítima de sífilis congênita. Rodrigo me explicou que Flávia se trata da doença, atualmente, mas logo eu descobriria algo que ele não me revelara nesta primeira entrevista: Flávia também é usuária de drogas. Enquanto grávida de Caroline, bebia, fumava e trabalhava. E deixou que Rodrigo assumisse, enfim, o papel de mãe da família, vivendo em função dos filhos em tempo integral, especialmente do mais velho, que apresenta uma condição psicopatológica ainda mais grave do que a de Caroline.

\section{Início do tratamento (jan-abr/2008)}

Passei a atender Caroline semanalmente, e a seu pai - quem costumava trazê-la -, em média, quinzenalmente.

Desde o início da análise de Caroline, nossos encontros lhe davam a oportunidade de repetir para elaborar, na transferência, situações traumáticas vividas passivamente por ela, diante das quais ela passava a assumir, deste modo, uma posição ativa. Freud (1920) já havia sinalizado que as crianças, no brincar, tendem a tecer este movimento, repetitivo, na tentativa de dominar o que um dia as dominou, no trauma.

Assim, Caroline manifestava sua dificuldade de suportar o término das sessões, sentido por ela como um abandono de minha parte, invertendo nossas posições: era eu quem anunciava que o tempo se esgotava; era ela, então, que me expulsava da sala e se trancava lá dentro; ou escapava para outra sala e não per- 


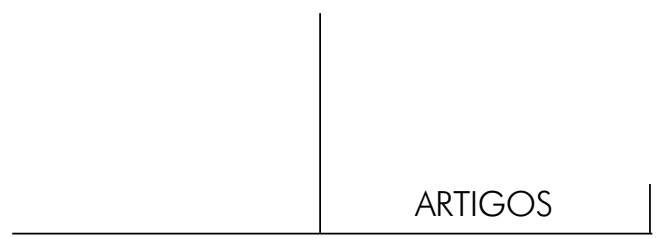

mitia que eu entrasse. Certa vez, fechou-se em uma sala, trancou as janelas e bloqueou a porta com uma mesa tão pesada que me questionei como uma criança tão pequena fora capaz de empurrá-la! Quando eu pedia para entrar, ela não permitia. Eu aguardava então, do lado de fora, o (inevitável) momento em que Caroline saía, para verificar se eu ainda estava à sua espera. Toda esta atuação era vivida por ela com muita angústia, muito choro, muitos gritos, apesar de minha fala repetidamente lhe assegurar que eu estaria ali para recebê-la novamente na semana seguinte, para lhe garantir que esta separação não consistia num sinônimo de abandono. Houve ocasiões em que ela chegou a me bater, deixando clara a função defensiva de sua agressividade. Alguns de seus desenhos desta época, ainda não figurativos, transmitiam uma imagem de caos e confusão (Fig. 3).

Figura 3
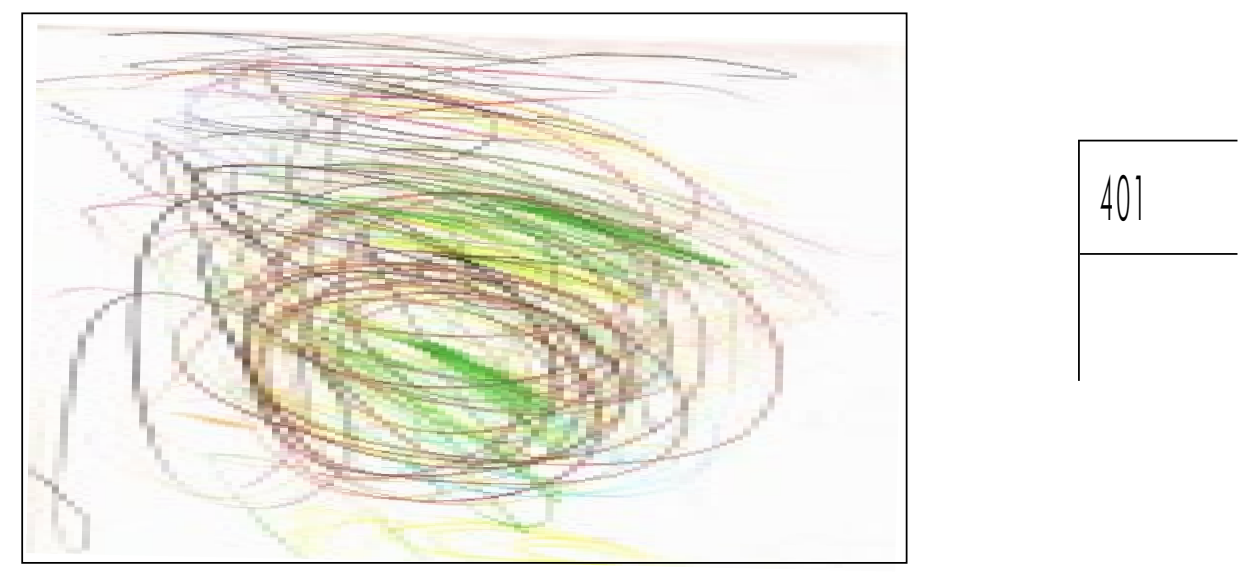

O trabalho psíquico empreendido por Caroline durante essas atuações nos remete à ilustração freudiana do brincar infantil, que se tornou conhecida como o jogo do fort-da (Freud, 1920). Este jogo, protagonizado por um bebê observado por Freud, buscava elaborar a oscilação entre a ausência e a presença da mãe, por meio de uma simples e solitária brincadeira. Repetindo o costume frequente entre os bebês de atirar objetos ao longe, esta criança atirava um carretel à distância, enquanto pronunciava a palavra alemã fort - sinalizando que o objeto se fizera ausente. Em seguida, recuperava o carretel, por um fio que se atinha a ele, pronunciando com júbilo a palavra $d a$ - sinalizando que o objeto se fazia presente novamente. Desta forma, o bebê conseguia atuar, repetidamente, na brincadeira, uma situação traumática sofrida passivamente por ele. 


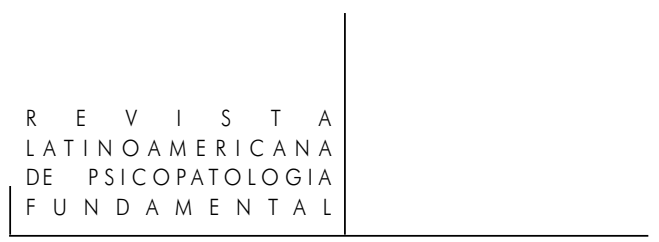

\section{A circunscrição de um sintoma (maio-out/2008)}

De modo semelhante, foi preciso um bom número de sessões - ou seja, de repetições dessa cena traumática, às vezes mais, às vezes menos intensamente para que Caroline construísse um laço de confiança na permanência da minha presença, investida transferencialmente como uma figura materna. Do decorrer dos atendimentos, novas questões passaram a assumir o centro da cena. Novos medos: principalmente do "bicho". Caroline abria e fechava a porta várias vezes, ligava e desligava a luz ou o ventilador da sala, e soltava gritos - num misto de medo e certo júbilo - convidando-me a me esconder com ela embaixo da mesa, para nos protegermos do "bicho". Verificava, pela janela, se o "bicho" estava por perto. Eu verificava também, ao seu lado, comentando que felizmente eu não avistava "bicho" algum. Passamos a conversar sobre o "bicho": eu lhe perguntava como ele era, onde morava, o que fazia. Ela me contava que ele era o "lobisomem", morava na floresta, pegava criancinha. Pouco a pouco, o "bicho" ganhava contornos no discurso e nos desenhos de Caroline: ela passou a representá-lo de maneiras diversas, mas sempre aproximadas à figura humana (Fig. 4 e 5).

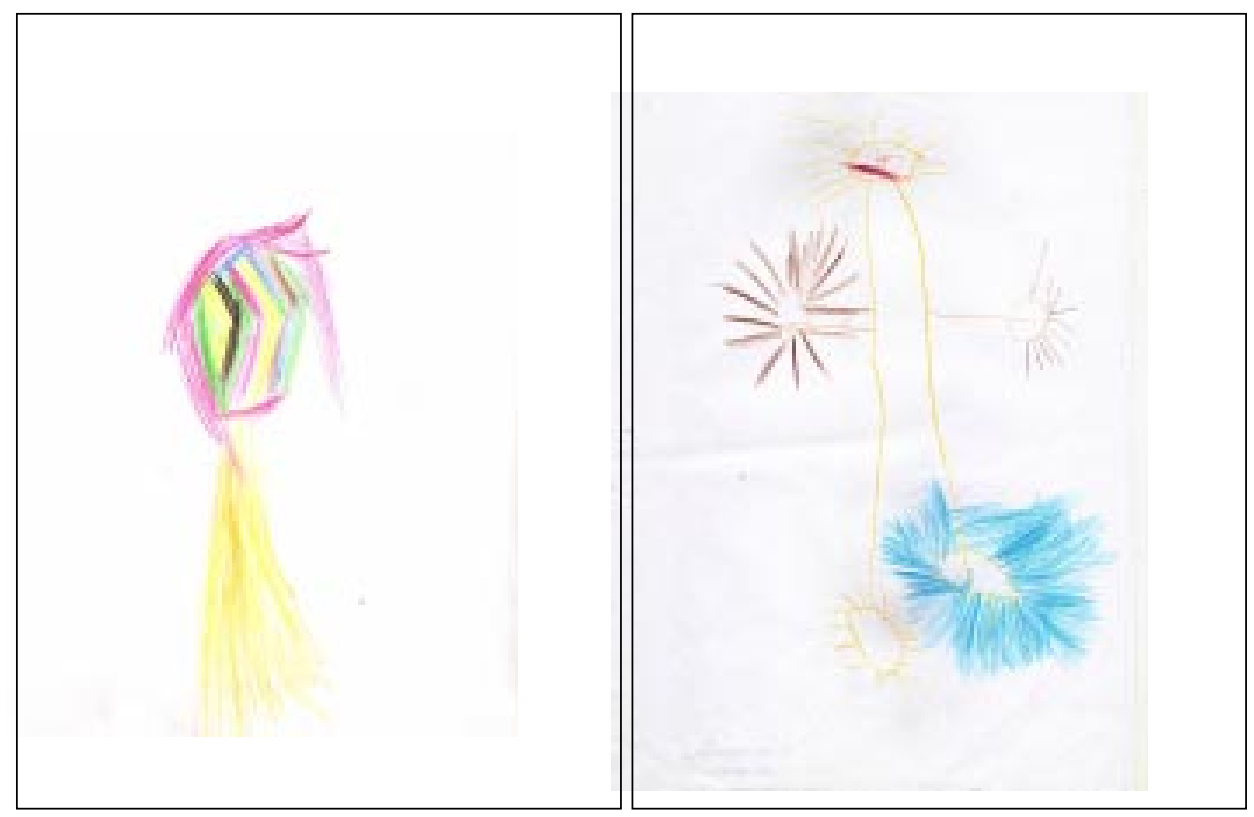

Rev. Latinoam. Psicopat. Fund., São Paulo, v. 13, n. 3, p. 395-411, setembro 2010 
Paralelamente, sugeri que Rodrigo também poderia realizar uma análise pessoal, após um novo episódio de oscilação de humor. Ele se disse interessado, "estou precisando mesmo" (sic), e passou a ser atendido por Viviane.

Também nesta fase, Caroline gostava muito de brincar com a cola: chegava a gastar um tubo inteiro somente em uma sessão. Sujava a mesa e as mãos e, eventualmente, me perguntava se eu iria bater nela por isso. Eu respondia que não e me oferecia para ajudá-la a ir ao banheiro, lavar as mãos, o que ela aceitava alegremente - e passou a me demandar diversas vezes. Parecia tranquila e independente no banheiro, aproveitando a ocasião para urinar; subia na privada para alcançar a descarga com seu bracinho, mas valorizava minha presença me pedindo para pegar o papel higiênico para ela.

Numa ocasião, depois que as idas ao banheiro deixaram de ser rotina nos atendimentos, ajudei-a a apontar os lápis de cor. E, durante várias sessões, ela reproduziu a ação de apontá-los, um por um, como se quisesse repetir algo que aprendera comigo. Cada vez mais, eu percebia que Caroline me colocava num lugar de mãe, uma mãe suficientemente boa, como diria Winnicott (1958), capaz de oferecer a ela um ambiente acolhedor propício à sua constituição como sujeito. Algumas vezes, invertia os papéis: brincava que ela era a mãe (ativa), eu a filha. Pedia para pentear meus cabelos. Queria usar minha bolsa e meus óculos escuros. O final de nossas sessões, em vez de dramático e conturbado como inicialmente, passou a ser marcado por uma boa dose de humor: eu saía da sala, pelo corredor do ambulatório, ainda usando algum penteado estapafúrdio que ela fizera - sempre utilizando a maior quantidade disponível de elásticos, prendedores, uma verdadeira festa! - e ela desfilava, mal conseguindo carregar minha bolsa em seu pequenino ombro, mal conseguindo sustentar meus óculos em seu pequenino nariz, com ares de dondoca que arrancavam risadas dos que estavam na sala de espera.

Pentear os cabelos, apontar um lápis, ou mesmo urinar e lavar as mãos, estas são obviamente atividades que requerem um certo olhar materno sobre a criança. Em outras palavras, é preciso que uma mãe ofereça a seu filho alguns cuidados básicos, relativos à higiene, passando pela aparência física, e chegando à educação propriamente dita. No caso de Caroline, sua mãe demonstrava uma dificuldade evidente de empreender esta tarefa, o que fazia com que a filha se engajasse numa verdadeira "busca por uma mãe", na qual obteve resultados parciais (transferenciais) em análise. O medo do desamparo e de se desintegrar, expressos por Caroline, apontavam esta falha da maternagem. Convém lembrar que Flávia não teve mãe, nem mesmo uma família, o que impossibilitava que ela própria ocupasse este enigmático papel de mãe.

O fato da eclosão dos sintomas coincidir com a entrada de Caroline na creche parece sugerir sua incapacidade - pela precariedade do acolhimento e dos 


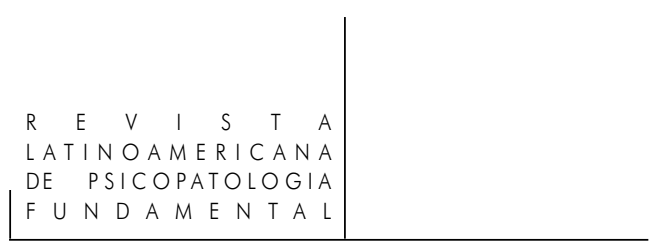

cuidados mais básicos demonstrada por ela - de se inserir num ambiente onde há regras culturais claras: há que se tomar banho na hora certa, obedecer à professora, respeitar os colegas etc.

\section{Atendimentos mais recentes (nov-dez/2008)}

O último relatório escolar solicitado, há dois meses, descreve uma mudança radical no comportamento de Caroline. Ela ainda se intimida diante de algumas figuras de autoridade - como o professor de Educação Física - mas sua agressividade reduziu drasticamente. É interessante notar como Caroline desenvolve suas próprias estratégias para se defender: na escola, por exemplo, elegeu uma faxineira como sua "pessoa favorita", com quem é muito apegada e carinhosa. O pai me contou também que Caroline tem se aproximado muito da avó materna: brinca de pentear o cabelo dela e, "se deixar, ela fica lá [na casa da avó] o dia todo" (sic).

Novos sintomas, então, passaram a ser relatados pelo pai, especialmente a enurese noturna de Caroline - que já existia ao início do tratamento, mas ele preferia elevar ao primeiro plano os sintomas manifestos na escola do que no ambiente familiar. Este segundo grupo de sintomas, portanto, passou a tematizar as sessões, tão logo as queixas antigas foram perdendo importância. Agora, Caroline trazia questões bastante comuns entre a maioria das crianças: o ciúme da irmã mais nova, por exemplo, que tinha o privilégio de dormir no quarto dos pais, enquanto ela, Caroline, deveria dormir no outro quarto, com os dois irmãos. Rodrigo contou que, às vezes, com medo, Caroline migrava, no meio da noite, para a cama do irmão - onde, curiosamente, jamais urinava. Contou também que ela tem medo de levantar-se à noite, para ir ao banheiro. Sublinhei esta associação entre o medo e a enurese, tão frequente entre as crianças desta idade. E Rodrigo disse que, "quando conversa direitinho" com ela, "geralmente ela não molha a cama" (sic). Elogiei a percepção de Rodrigo de que é importante conversar com sua filha, e ele respondeu que ele "nem bate tanto", "quem bate mais é a mãe dela" (sic).

Trabalhando em análise seu desejo de ocupar na família um lugar de pai, Rodrigo arranjou um emprego temporário numa obra do PAC. Flávia passou a trazer Caroline - normalmente muito atrasada e trazendo os outros filhos a tiracolo. Outro momento da análise foi inaugurado: Caroline passou a tematizar seus medos de forma cada vez mais rica. Desenhou uma "cobra", com cinco "cobrinhas" na barriga e, quando perguntei seus nomes, ela identificou cada cobrinha com o nome de si e de seus irmãos. Desenhou outra figura e disse: "Esse aí é o 
lobisomem. O pai não tem cabeça" (sic) (Fig. 6). A figura do "lobisomem", criatura terrível de noite, mas humana de dia, parecia remeter à figura do pai, que deseja construir um lar e uma família, porém também apresenta suas próprias dificuldades de consegui-lo.

Figura 6

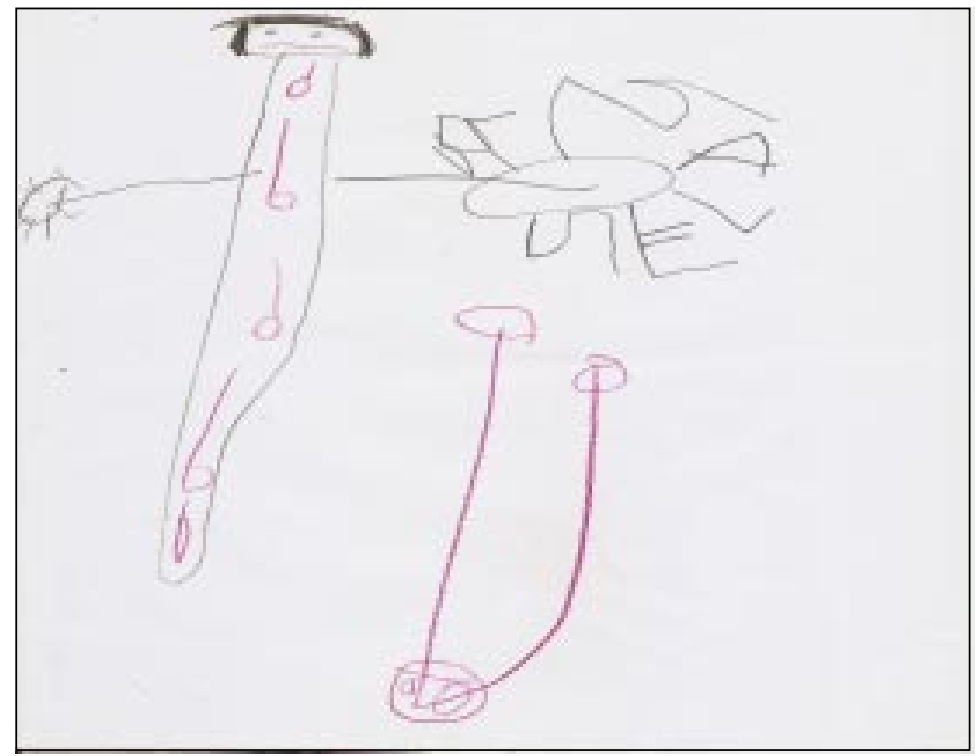

Em outro desenho (Fig. 7), Caroline representou a "casa da Neve", muito distante, "lá no céu", e disse que a Neve era sua irmãzinha, que "morava no céu". Seja para elaborar a morte da irmã que faleceu ainda bebê, seja para realizar no brincar sua fantasia de que a irmã mais nova desapareça, este desenho traz novos elementos para a continuidade da análise de Caroline. Da mesma forma, a possibilidade de interlocução com Flávia - até hoje escassa e limitada - também deve ser doravante explorada.

Concluímos, portanto, que, após pouco mais de um ano de atendimento, os sintomas de desamparo e desestruturação, atuados por Caroline, foram substituídos por outros, menos radicais e mais indicadores de sua constituição como sujeito, inevitavelmente dotado de conflitos psíquicos - um dos resultados esperados de uma análise, conforme Freud. Antes mesmo de postular a primazia do 
inconsciente, o pai da psicanálise já compreendera que "haverá muito a ganhar se conseguirmos transformar [o] sofrimento histérico" - concretizado, então, em flagelos do corpo - "numa infelicidade comum. Com uma vida mental restituída à saúde, [o paciente] estará mais bem armado contra essa infelicidade" (Freud; Breuer, 1895, p. 316).

\section{Figura 7}

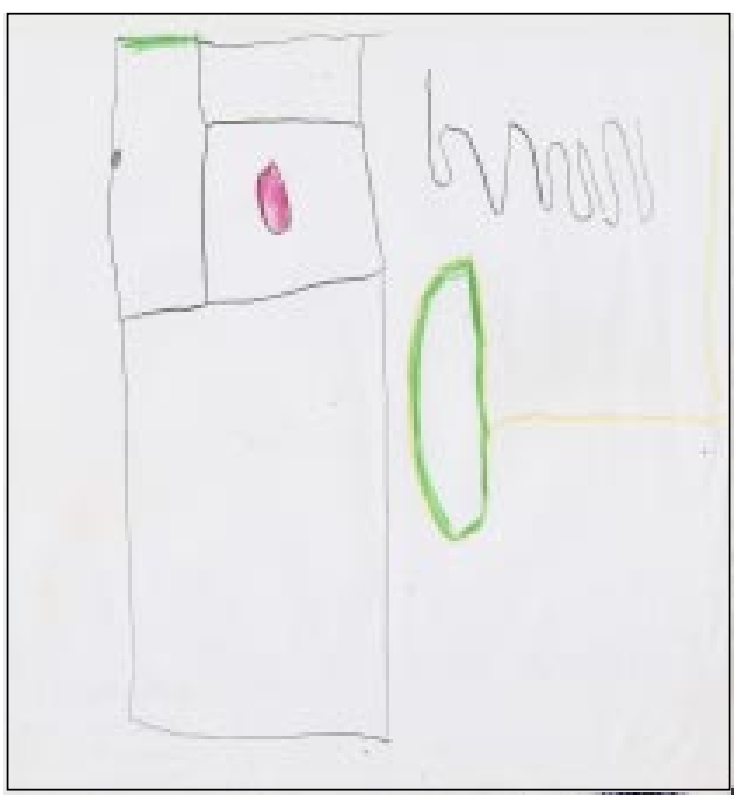

Atendimento a Rodrigo, pai de Caroline $^{2}$

Diante das bruscas oscilações de humor apresentadas por Rodrigo, percebemos a necessidade de oferecer a ele um espaço de escuta individualizada.

Já na primeira sessão, Rodrigo falou do seu dia-a-dia agitado, com quatro crianças para cuidar, vendo-se às vezes nervoso, sem paciência e sobrecarregado: "Não posso contar com ninguém" (sic).

2. Atendimento realizado e relatado por Viviane Chan.

Rev. Latinoam. Psicopat. Fund., São Paulo, v. 13, n. 3, p. 395-411, setembro 2010 


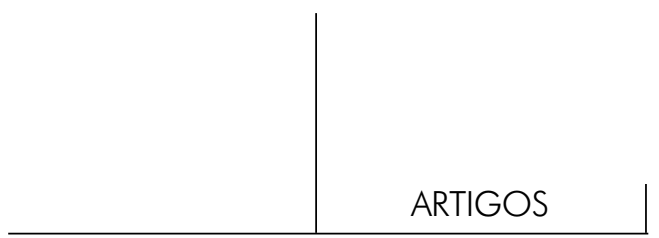

Frequentemente, vinha às sessões acompanhado do filho maior, Fábio, o qual não podia deixar sozinho por conta de seu problema psiquiátrico. As sessões eram muitas vezes interrompidas por Fábio que, a pedido meu, aguardava (ansioso) do lado de fora da sala. Com a inquietação de Fábio, Rodrigo se preocupava e, às vezes, não era possível usar todo o tempo reservado para o atendimento.

Rodrigo é o filho mais velho de uma família de nove irmãos. Disse que nunca teve um pai que o ajudasse, nem que desse a ele um apoio moral. Aos dez anos, Rodrigo foi morar com a tia que o criou até os 15, quando faleceu - e Rodrigo foi morar na rua. Ele diz que aprendeu a cuidar da casa e da família com essa tia. Conheceu Flávia na rua, ambos trabalhavam em um estacionamento. Com o nascimento do primeiro filho, resolveram "sair da rua" (sic).

Estava desempregado há quatro meses. Desde então, Flávia trabalhava enquanto Rodrigo cuidava da casa e dos filhos. Nas primeiras sessões, trazia os compromissos médicos e os cuidados com as crianças como impedimentos para voltar a trabalhar. Rodrigo preocupava-se porque, segundo ele, Flávia não tinha paciência com as crianças, e ficava mais tranquilo em casa cuidando dos filhos.

Logo, Rodrigo começou a falar do seu desejo de voltar a trabalhar, pois, agora, Flávia estava mais calma e paciente com os filhos. Nas sessões seguintes, o tema deixou de ser os cuidados com as crianças, e Rodrigo passou a falar das vagas de emprego em uma obra na comunidade onde mora e da expectativa de ser contratado. Hoje, Rodrigo está trabalhando e, na maioria das vezes, quem traz Caroline aos atendimentos é Flávia.

Rodrigo estava sendo atendido por mim há cinco meses, porém as sessões eram muito espaçadas por conta das faltas consecutivas do mesmo e, às vezes, porque trazia seu filho maior, o qual não podia ficar desacompanhado.

Contudo, percebemos o quanto foi importante para Rodrigo este espaço de escuta.

\section{Considerações finais}

Em um dos raros momentos em que discorreu sobre a psicanálise com crianças, Freud (1933) nos ensinou que

As resistências internas que combatemos nos adultos são substituídas na criança, na maioria das vezes, por dificuldades externas. Quando os pais se erigem em portadores da resistência, amiúde periga a meta da análise ou ela mesma, e por isso torna-se necessário juntar à análise da criança algum influxo analítico sobre os progenitores. (p. 137)

Rev. Latinoam. Psicopat. Fund., São Paulo, v. 13, n. 3, p. 395-411, setembro 2010 
Em nossa prática, percebemos que o "influxo analítico sobre os progenitores", ao qual se refere Freud, pode ter efeitos não apenas sobre a resistência dos pais, que ameaça a condução da análise dos filhos. Este influxo pode ter efeitos também sobre uma estreita relação estabelecida entre o sintoma da criança e as projeções parentais de conflitos infantis - relação respaldada por estudos inovadores acerca da psicanálise com bebês e suas famílias (Lebovici, 1994; Cramer, Palacio-Espasa, 1993; Fraiberg, Adelson, Shapiro, 1983).

$\mathrm{O}$ atendimento realizado com Rodrigo teve como foco a reconstrução de sua história e a da criança. Através deste tipo de atendimento aos responsáveis, pretende-se ajudá-los a atenuar ou reintrojetar os elementos inconscientes projetados no filho, possibilitando assim aos pais elaborar entraves inerentes ao processo de parentalidade (Cramer, Palacio-Espasa, 1993).

Assim como o pai, a mãe de Caroline também foi convidada, desde o início, a participar do tratamento da filha, mas manteve-se distante, em virtude de suas dificuldades ou de seu próprio desinteresse - os quais nos apareciam, justamente, através dos sintomas de Caroline, que apontavam para uma falta da maternagem.

Lançando-se um olhar sobre o psiquismo da criança em formação, é fundamental, portanto, perceber a complexa rede de relações individuais, familiares e transgeracionais que estão presentes na formação de seu sintoma. Neste sentido, oferecer aos pais uma oportunidade de elaborar conflitos transmitidos de uma geração a outra pode produzir, como resultado, a liberação da criança do ônus de dar forma, por via sintomática, às projeções parentais.

\section{Referências}

Aberastury, A. Psicanálise da criança: teoria e técnica. Porto Alegre: Artes Médicas, 1982.

Cramer, B.; Palacio-Espasa, F. Les psychothérapies mères-bébés: études cliniques et techniques. Paris: PUF, 1993.

Fraiberg, S.; Adelson, E.; Shapiro, V. Fantômes dans la chambre d'enfants. Psychiatrie de l'enfant, v. XXVI, n. 1, p. 57-97, 1983.

Freud, S.; Breuer, J. (1895). Estudos sobre a histeria. In: Edição Standard Brasileira das Obras Psicológicas Completas de Sigmund Freud. Rio de Janeiro: Imago, 1996. v. II.

Freud, S. (1909). Análise da fobia de um menino de cinco anos. In: Edição Standard Brasileira das Obras Psicológicas Completas de Sigmund Freud. Rio de Janeiro: Imago, 1977. v. X.

Rev. Latinoam. Psicopat. Fund., São Paulo, v. 13, n. 3, p. 395-411, setembro 2010 


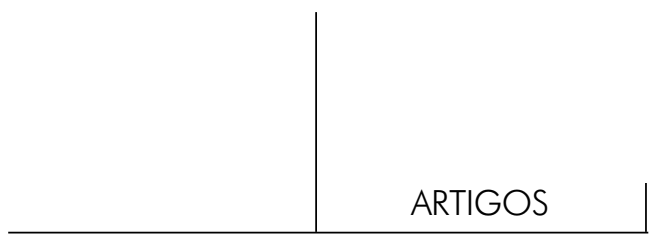

. (1914). Recordar, repetir e elaborar: novas recomendações sobre a técnica da psicanálise II. In: Edição Standard Brasileira das Obras Psicológicas Completas de Sigmund Freud. Rio de Janeiro: Imago, 1969. v. XII.

. (1920). Além do princípio de prazer. In: Edição Standard Brasileira das

Obras Psicológicas Completas de Sigmund Freud. Rio de Janeiro: Imago, 1977. v. XVIII.

. (1933). Novas conferências introdutórias sobre psicanálise. In: Edição

Standard Brasileira das Obras Psicológicas Completas de Sigmund Freud. Rio de Janeiro: Imago, 1969. v. XXII.

LaCan, J. (1969). Deux notes sur l'enfant. Ornicar, Paris, n. 37, p. 13-14, 1986.

Lebovici, S. Les interactions fantasmatiques. Rev. de Méd. Psychosomathique, n. 37/ 38, p. 39-50, 1994.

Winnicott, D. W. (1958). Da pediatria à psicanálise. Rio de Janeiro: Imago, 2000.

\section{Resumo}

(Analysis of the helplessness of a five-year old girl)

Based on the case of a five-year-old girl, we present here a working method developed at a public clinic specialized in the psychoanalysis of children. We discuss the importance of a specific methodology for psychoanalytic treatment of children, whereby both children and parents are treated separately by the same psychologist. The conclusions indicate the usefulness of this approach for the children's mental health.

Key words: Child psychoanalysis, public clinic, reatment of parents

(Analyse de la détresse d'une fille de cinq ans)

Dans cet article, nous présentons la méthode de travail développé dans une clinique publique spécialisée dans le soin psychanalytique des enfants à travers le rapport du cas clinique d'une fille de cinq ans. Cette étude montre l'importance d'une méthodologie spécifique au traitement psychanalytique de l'enfant, où elle et ses parents sont accueillis par le même psychologue à des moments différents. Les résultats montrent la pertinence de cette modalité de traitement pour la santé mentale de l'enfant.

Mots clés: Psychanalyse de l'enfant, clinique publique, accompagnement des parent

(Análisis del desamparo de una niña de cinco años)

En este artículo presentamos el método de trabajo desarrollado en un ambulatorio público especializado en la atención psicoanalítica de niños, relatando 


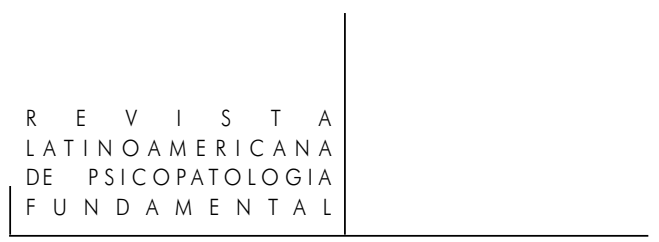

el caso clínico de una niña de cinco años. Este estudio muestra la importancia para el tratamiento psicoanalítico del niño de una metodología específica, donde el niño y sus padres son atendidos por la misma psicóloga, en horarios diferentes. Los resultados muestran la relevancia de esta modalidad de tratamiento para la salud mental de los niños.

Palabras claves: Psicoanálisis de niños, ambulatorio público, atención a los padres

Citação/Citation: Dadoorian, D.; Oliveira, F.H. DE; Chan, V. Análise do desamparo de uma menina de cinco anos. Revista Latinoamericana de Psicopatologia Fundamental, São Paulo, v. 13, n. 3, p. 395-411, set. 2010.

Editor do artigo/Editor: Prof. Dr. Manoel Tosta Berlinck

Recebido/Received: 6.7.2009 / 7.6.2009 Aceito/Accepted: 18.9.2009 / 9.18.2009

Copyright: () 2009 Associação Universitária de Pesquisa em Psicopatologia Fundamental/ University Association for Research in Fundamental Psychopathology. Este é um artigo de livre acesso, que permite uso irrestrito, distribuição e reprodução em qualquer meio, desde que o autor e a fonte sejam citados/This is an open-access article, which permits unrestricted use, distribution, and reproduction in any medium, provided the original author and source are credited.

Financiamento/Funding: As autoras declaram não terem sido financiadas ou apoiadas/The authors have no support or funding to report.

Conflito de interesses/Conflict of interest: As autoras declaram que não há conflito de interesses/The authors declare that has no conflict of interest.

\section{Diana Dadoorian}

Doutora em Psicologia Clínica e Psicopatologia pela Universidade Paris VIII/França; Psicóloga; Psicanalista do Instituto de Psiquiatria da Universidade Federal do Rio de Janeiro - UFRJ (Rio de Janeiro, RJ, Brasil); Coordenadora adjunta do Curso de Especialização em Saúde Mental da Infância e Adolescência do Instituto de Psiquiatria da Universidade Federal do Rio de Janeiro - IPUB/UFRJ (Rio de Janeiro, RJ, Brasil); Coordenadora do Grupo de Pesquisa "A clínica contemporânea com crianças e adolescentes"; Membro da Associação Brasileira de Estudos sobre o Bebê - Abebê (Brasília, DF, Brasil).

Instituto de Psiquiatria da Universidade Federal do Rio de Janeiro - UFRJ

Serviço de Psiquiatria da Infância e da Adolescência

Av. das Américas, 4200, bl .2, s/208

22640-102 Rio de Janeiro, RJ, Brasil

Fone: (21) 2513-5770

e-mail: d.dadoorian@gmail.com 


\section{ARTIGOS}

\section{Fernanda Hamann de Oliveira}

Psicanalista; Mestranda do Programa de Pós-Graduação em Teoria Psicanalítica da Universidade Federal do Rio de Janeiro - UFRJ (Rio de Janeiro, RJ, Brasil), com título de especialista em Saúde Mental da Infância e da Adolescência pelo Instituto de Psiquiatria da Universidade Federal do Rio de Janeiro - UFRJ.

Rua Visconde de Silva, 102/503

22271-044 Rio de Janeiro, RJ, Brasil

e-mail: fehamann@hotmail.com

\section{Viviane Chan}

Psicóloga; Especializanda em Saúde Mental da Infância e da Adolescência pelo Instituto de Psiquiatria da Universidade Federal do Rio de Janeiro - UFRJ (Rio de Janeiro, RJ, Brasil).

Rua Washington Luiz, 50/402

20230-025 Rio de Janeiro, RJ, Brasil

e-mail: vivipsichan@hotmail.com 